\title{
Electronic Service Quality: Public Transport Information on the Internet
}

\author{
Lars Eriksson and Margareta Friman, Karlstad University \\ Ann-Catrin Norman, The Swedish Social Insurance Agency
}

\begin{abstract}
As public transport companies market new self-service technologies, it has become increasingly important to understand the factors affecting the users' perceived service quality of these services. Electronic Service Quality has been broadly defined as encompassing all phases of a customer's interaction with a website. The E-S-QUAL scale comprises four dimensions. This article investigates the importance of three of the suggested quality dimensions (efficiency, system availability, and fulfillment) for overall satisfaction when using information-based websites. A survey was conducted with respondents being asked to use and evaluate an existing website delivering public transport information in their region. The results revealed that efficiency (addressing the ease and speed of using the site) was most important for overall satisfaction. Furthermore, it is concluded that a modified E-S-QUAL scale is appropriate for this purpose as it was possible to adapt it to a pure service-related website.
\end{abstract}

\section{Introduction}

Many public transport companies have established websites as a complement to their existing services where customers can view and download travel-related information. A common service provided to passengers is the ability to make inquiries regarding arrival and departure times, prices, and the nearest stops. It is 
believed that the extra cost invested in providing additional information via the Internet will eventually generate more journeys and more passengers.

Research into e-commerce and technology adoption suggests that a user-friendly website with rich, interesting, and searchable contents will ultimately gain the approval of customers, encouraging both initial use and return visits (e.g., Bell and Tang 1998; Liu and Arnett 2000; Zhang and Von Dran 2001). Conversely, a website with poor content and design, especially when the services are difficult to use, will likely generate negative feelings (Mick and Fournier 1998). Thus, the way the site is organized to make the content easier to read and the service easier to use can have a significant impact on the level of satisfaction with the service. Taken together, high levels of service quality will encourage both a higher level of satisfaction and a higher level of usage. Previous research largely focuses on online shopping sites. To complement this, the present research focuses on travel information sites where one can obtain information making it easier to use ordinary travel services.

\section{Using the Internet to Find Travel-Related Information}

When planning a journey, the Internet may be a source of help for some people. In recent years, travel-related websites have undergone considerable growth and the number of passengers making inquiries on the Internet seems to be on the increase. This may be due to the added convenience of online passenger websites (e.g., passengers are able to view different alternatives at any time). The service provided on these websites is free to the passenger. If passengers are dissatisfied with the service being provided, this may affect their travel behavior. An objective of the present study is to examine passengers' perceptions regarding overall satisfaction with the information site and how these perceptions relate to the defined dimensions of service quality.

If public transport companies are able to determine the underlying dimensions of service quality that are relevant to public transport information on the Internet, they may also be better able to design websites providing users with the highest possible service quality. In addition, if they have a tool for measuring users' perception of the level of service quality, they may also be able to adjust their service to retain current passengers and encourage new passengers to use their site. Thus, an additional objective of the present study is to provide an evaluation tool for assisting public transport companies in quantifying their service quality levels. 


\section{Previous Research into Electronic Service Quality}

Traditional research into service quality has measured the service quality of exchanges that are interpersonal in nature. However, recent studies have focused on evaluating electronic service quality (i.e., Aladwani and Palvia 2002; Yoo and Donthu 2001; Parasuraman, Zeithaml, and Malhotra 2005; Wolfinbarger and Gilly 2003; Yee-Man Siu and Chi-Wah Mou 2005). A recent study by Yang et al. (2005) developed an instrument measuring service quality in the context of an information service on the Internet. The results revealed five dimensions: usability, usefulness of content, adequacy of information, accessibility, and interaction. Usability is related to user-friendliness. Usefulness of content refers to the value, reliability, currency, and accuracy of the information. Adequacy of information is the extent of the completeness of the information. Accessibility involves availability and responsiveness. Interaction involves three types: users and employees, users and the website, and between peer users of similar products (Yang et al. 2005). The five factors significantly affected the users' overall service quality evaluation, which in turn influenced their satisfaction. Usability and accessibility were found to be the most significant influences on the users' overall service quality perceptions (Yang et al. 2005).

The eTailQ scale was developed in an attempt to measure how consumers perceive the quality of a website (Wolfinbarger and Gilly 2003). This scale comprises four dimensions: website design, reliability/fulfillment, privacy/security, and customer service. However, Parasuraman, Zeithaml, and Malhotra (2005) express reservations about two of the dimensions in the eTailQ scale (website design and customer service) as being less consistent and distinct. Having surveyed a number of relevant articles in this area, Parasuraman, Zeithaml, and Malhotra (2005) developed and refined a new scale for measuring electronic service quality (E-SQUAL-Electronic Service QUALity). The E-S-QUAL instrument has been tested in online shopping contexts. The dimension of efficiency addresses the ease and speed of accessing and using the site, system availability focuses on the technical functioning of the site, fulfillment measures the extent to which the site's promises regarding order delivery and item availability are fulfilled, and privacy considers the degree to which the site is safe and protects customer information. In the context of e-commerce, efficiency and fulfillment have the greatest effect on the perceived service quality, value and loyalty, followed by the dimensions of system availability and privacy. 
E-S-QUAL is a multiitem scale developed for measuring the service quality delivered by websites where customers shop online. So far, the E-S-QUAL instrument has focused on websites selling physical products. It should, however, be tested in other contexts as well. Parasuraman, Zeithaml, and Malhotra (2005) call for further research into E-S-QUAL in the context of pure service sites (sites offering information services). The present study addresses this issue by investigating the impact of three of the dimensions of the E-S-QUAL scale on user satisfaction with public transport information on the Internet.

\section{Method}

\section{Respondents}

The sample included 58 people-41 women and 17 men-living in Karlstad, Sweden. Respondents were conveniently selected at the university and among acquaintances of the authors. Their mean age was 35.0 years $(S D=10.7)$. All but two of the respondents had their own computer and access to the Internet. The majority (83\%) had been using the Internet for five years or more. Seventy-one percent reported that they use the Internet once a day on average, 24 percent use the Internet more than once a week on average, and a few respondents $(n=3)$ use the Internet more than once a month on average.

Twenty-nine percent reported that they use public transport more than once a week on average, 26 percent use public transport more than once a month on average, 36 percent use public transport more than once a year on average, and 9 percent seldom or never use public transport. Twenty-four percent reported that they use public transport information on the Internet more than once a month on average, the majority (52\%) use it more than once a year on average, and 24 percent seldom or never use public transport information on the Internet.

\section{Procedure}

Respondents were asked to use and evaluate an existing website delivering public transport information in their region. Thereafter, they were asked to fill out a booklet consisting of three parts. Questions aimed at describing the sample were asked in the first part. The descriptives included gender, age, and measures of Internet experience. They also estimated how frequently they used the Internet, public transport, and public transport information on the Internet (never, a few times per year, a few times per month, a few times per week, or daily). 
In the second part, respondents were asked to: (1) go to the prespecified website; (2) imagine making a predefined journey from one specified location to another specified location; and (3) search for and report on the departure time, arrival time, and cost of the stated trip. Respondents were also asked to specify the type of transportation and describe the entire journey (including any changes). The purpose of the task was to have respondents test the service to subsequently be able to evaluate it. Respondents were also permitted to make suggestions for improvements. In the third part, they rated their perceptions of the electronic service quality on 20 questions.

\section{Instruments}

Website. An existing website delivering public service information in the area where the respondents were living was used in this study (Figure 1). This website contains information about all buses and trains in the County of Värmland, Sweden (http://www.kollplatsen.com/, accessed April 2005).

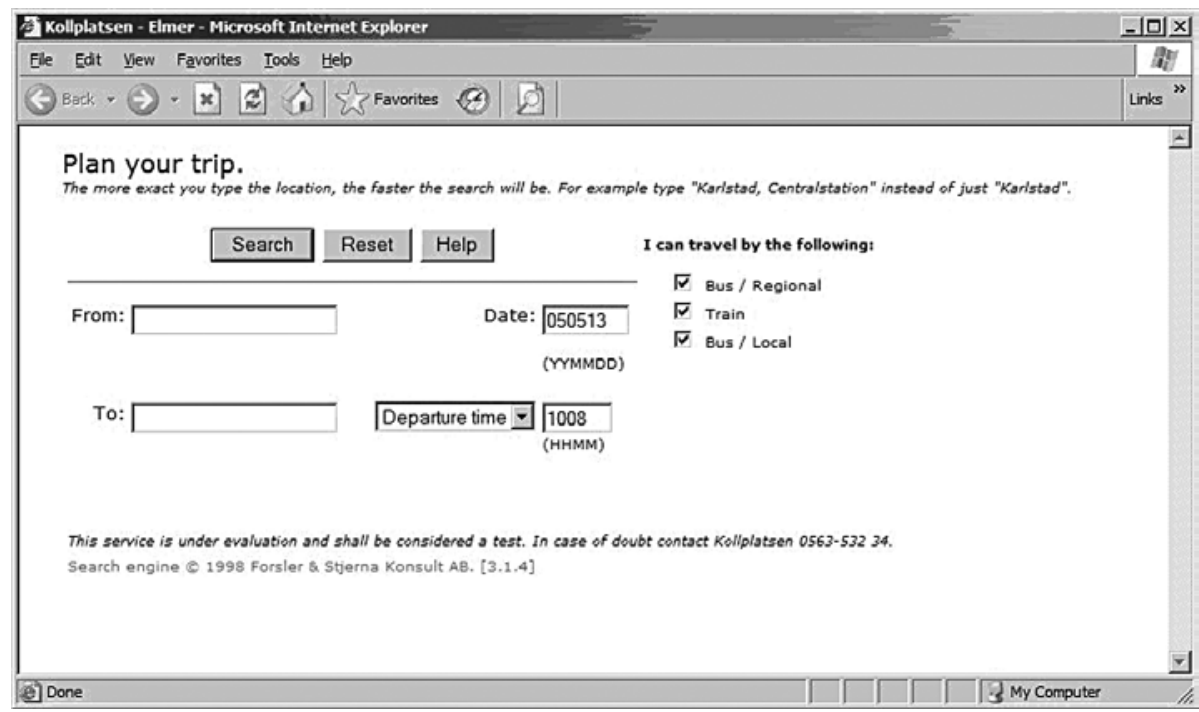

Figure 1. The Website's Inquiry Page (translated from Swedish to English) 
E-S-QUAL-A Multiple-Item Scale for Assessing Electronic Service Quality. Parasuraman, Zeithaml, and Malhotra (2005) developed E-S-QUAL for measuring the service quality delivered by websites where customers shop online. The E-S-QUAL scale was originally a four-dimensional, 22-item scale. Items included in E-S-QUAL were selected after extensive pretesting that included multivariate analyses (Parasuraman, Zeithaml, and Malhotra 2005). The original scale was modified in this study to adjust it to the context of a pure service transportation site (see Figure 2 for the scale items).

\begin{tabular}{ll} 
& Efficiency \\
\hline EFF1 & This site makes it easy to find what I need. \\
EFF2 & It makes it easy to navigate anywhere on the site. \\
EFF3 & It enables me to complete a question quickly. \\
EFF4 & Information on this site is well organized. \\
EFF5 & It loads the pages fast. \\
EFF6 & This site is simple to use. \\
EFF7 & This site enables me to get on to it quickly. \\
EFF8 & This site is well organized. \\
& System Availability \\
\hline SYS1 & This site is always available for use. \\
SYS2 & This site launches and runs straight away. \\
SYS3 & This site does not crash. \\
SYS4 & Pages on this site do not freeze after I have entered my order information. \\
& Fulfillment \\
\hline FUL1 & It delivers what it promises. \\
FUL2 & This site makes information available within a suitable time frame. \\
FUL3 & It quickly delivers what l'm looking for. \\
FUL4 & It delivers the quickest route. \\
FUL5 & It presents alternatives to the route I asked for. \\
FUL6 & It delivers the correct information. \\
FUL7 & It delivers exactly what I'm looking for. \\
FUL8 & It delivers the journey time on the route I asked for. \\
& Overall satisfaction \\
\hline TFU1 & In general, the service is satisfactory. \\
TFU2 & Across the board, the service works well. \\
I will use the service again. \\
\end{tabular}

\section{Figure 2. Measures of Study Constructs}


Eight items were included to tap efficiency, four items were included to tap system availability, and eight items were included to tap fulfillment. One dimension (privacy), included in the original scale, was excluded from this study since it relates solely to web shopping behavior.

Overall Satisfaction. A third set of three questions was used to measure overall satisfaction: (1) "In general, the service is satisfactory," (2) "Across the board, the service works well," and (3) "I will use the service again." All the ratings on E-S-QUAL and overall satisfaction were made on a numerical scale ranging from 1 (strongly disagree) to 5 (strongly agree).

\section{Results}

\section{Questionnaire Measures}

The E-S-QUAL scales were averaged to yield three indices corresponding to efficiency, system availability, and fulfillment. The reliability of these indices was satisfactory, as indicated by Cronbach's alphas of 0.91 (efficiency), 0.81 (system availability), and 0.76 (fulfillment). These figures are comparable to those reported in previous research (Parasuraman, Zeithaml, and Malhotra 2005).

A measure of the overall satisfaction was constructed by averaging across the three overall scales. A satisfactory Cronbach's alpha of 0.76 was obtained. Table 1 shows means, SDs, and intercorrelations between the four indices and the four background questions about respondents' Internet and public transport experiences.

As expected, the relationship between Internet experiences and use of the Internet was positive and statistically significant $(r=0.61)$. This was also the case for Internet experiences and system availability $(r=0.27)$. This relationship was weak, although statistically significant. It can thus be concluded that Internet experiences show a positive association with use of the Internet and the perceived system availability.

The relationship between use of the Internet and use of public transport information on the Internet was significant $(r=0.30)$. This was also the case for Internet use and system availability $(r=0.30)$. It can thus be concluded that use of the Internet shows a positive association with use of public transport information on the Internet and the perceived system availability. 


\section{Table 1. Correlations, Means (M), and Standard Deviations (SD) of Index Variables and Background Questions}

\begin{tabular}{lccccccccc}
\hline Question & & $\mathbf{V 1}^{1}$ & $\mathbf{V}^{2}$ & $\mathbf{V 3}$ & $\mathbf{V}^{2}$ & $\mathbf{V 5}^{\mathbf{3}}$ & $\mathbf{V 6}^{2}$ & V7 & V8 \\
\hline Internet experiences & {$[\mathrm{V} 1]$} & 1.00 & & & & & & & \\
Use of Internet & {$[\mathrm{V} 2]$} & $.61^{*}$ & 1.00 & & & & & & \\
Use of public transport & {$[\mathrm{V} 3]$} & -.25 & -.04 & 1.00 & & & & & \\
Use of public transport & {$[\mathrm{V} 4]$} & .21 & $.30^{*}$ & $.51^{*}$ & 1.00 & & & & \\
information on the Internet & & & & & & & & & \\
System availability & {$[\mathrm{V} 5]$} & $.27^{*}$ & $.30^{*}$ & -.15 & .10 & 1.00 & & & \\
Overall satisfaction & {$[\mathrm{V} 6]$} & -.14 & .02 & .14 & .18 & $.62^{*}$ & 1.00 & & \\
Efficiency & {$[\mathrm{V} 7]$} & -.14 & -.06 & -.04 & .01 & $.60^{*}$ & $.83^{*}$ & 1.00 & \\
Fulfillment & {$[\mathrm{V} 8]$} & -.13 & -.10 & .09 & .03 & $.46^{*}$ & $.66^{*}$ & $.77^{*}$ & 1.00 \\
\hline M & & 4.72 & 4.66 & 2.91 & 2.00 & 3.80 & 2.84 & 2.74 & 2.98 \\
SD & & 0.72 & 0.58 & 1.22 & 0.70 & 0.93 & 1.01 & 0.86 & 0.86 \\
\hline
\end{tabular}

Use of public transport was positively associated with use of public transport information on the Internet $(r=0.51)$.

The relationship between system availability and overall satisfaction was found to be positively and strongly related $(r=0.62)$. Thus, as the perceived system availability rises, so too does the overall satisfaction. A positive and strong correlation was also found between overall satisfaction and efficiency $(r=0.83)$ and overall satisfaction and fulfillment $(r=0.66)$. It can thus be concluded that overall satisfaction with public transport information on the Internet is positively associated with availability, efficiency, and fulfillment, but shows no association (see Table 1) with use of the Internet, use of public transport information on the Internet, or use of public transport.

\section{Regression Analyses}

A multiple regression analysis was performed with overall satisfaction as dependent variable and efficiency, system availability, and fulfillment as independent variables. The association between the dependent and independent variables was high $\left(R^{2}\right.$ adjusted $\left.=0.67\right)$. However, only efficiency (beta $=0.70, p<0.001$ ) was positively and significantly related to overall satisfaction (see Table 2 ). 


\section{Table 2. Multiple Regression of Predictors of Overall Satisfaction}

\begin{tabular}{lccc}
\hline Variable & Beta & $t$ & $p$ \\
\hline System availability & 0.18 & 1.88 & .067 \\
Efficiency & 0.70 & 5.14 & .001 \\
Fulfillment & 0.01 & 0.08 & .939 \\
\hline
\end{tabular}

\section{Accuracy of Performance}

In the part where respondents searched for and reported on the departure time, the arrival time, and the cost of the stated journey, 18 respondents stated an incorrect price while 7 stated the correct price. Thirty-three respondents did not answer the question. Many commented on the question by saying that it was difficult to find the price of the journey. One reason was the lack of information about the zone system on which the pricing structure is based.

Half of the respondents (29) chose to travel by a direct bus route, 20 respondents chose to combine trains and buses, 4 respondents combined regional and local buses, and 5 respondents did not state any chosen form of transport.

Forty-eight respondents gave a correct description of the route between the specified locations. Seven respondents failed to state a correct route. Three respondents did not answer the question.

Forty-five respondents took the opportunity to suggest improvements (see Table 3). Many suggestions concerned details of prices (e.g., "link the price directly to the

\section{Table 3. Overview of Suggested Improvements}

\begin{tabular}{lr}
\hline Category & Frequency \\
\hline Improved price lists & 12 \\
Clear and comprehensive information & 10 \\
Specify price in conjunction with inquiry results & 8 \\
Information about zones & 6 \\
Simplified inquiries & 3 \\
Display alternative journeys in conjunction with inquiry results & 3 \\
Miscellaneous & 3 \\
Have not submitted any suggested improvements & 13 \\
\hline Total & $\mathbf{5 8}$ \\
\hline
\end{tabular}


inquiry result" or "more readily available price lists") and more clear and comprehensive information (e.g., "display more suggested journeys on the same screen"). In summary, the majority of the respondents felt that there was a lack of information about both the price and the zone system on which the pricing structure was based. Suggested improvements specified by the respondents overwhelmingly relate to price information and the clarity of the website.

\section{Discussion and Conclusions}

One objective of the present study was to examine passengers' overall satisfaction empirically with a public transport information site and how overall satisfaction relates to dimensions of service quality. We used a modified multiitem version of the E-S-QUAL scale for measuring the service quality. Thus, an additional objective of this research was to propose an evaluation tool for assisting public transport companies in quantifying their service quality level on the Internet. Consequently, the contribution made by this research is twofold. First, it shows that experiences and use of the Internet increase the probability of using public transport information on the Internet. This indicates the potential growth and development of online information since the number of Internet users does not seem to be decreasing.

Second, efficiency, system availability, and fulfillment are all positively associated with overall satisfaction (Wolfinbarger and Gilly 2003; Parasuraman, Zeithaml, and Malhotra 2005; Yang et al. 2005; Yee-Man Siu and Chi-Wah Mou 2005). Thus, as the perceived efficiency, system availability, and fulfillment rise, so too does the overall satisfaction. More importantly, efficiency (the ease and speed of accessing and using the site) is the most critical contributor to the users' perceptions regarding overall satisfaction. The effect of efficiency on the dependent variable was positive and significant, whereas the effects of system availability and fulfillment were nonsignificant. The consistency of this result underscores the need for public transport companies to place extra emphasis on the website attributes pertaining to this dimension. One plausible explanation for the nonsignificant effects could be that the efficiency dimension is relatively important and a core dimension (Yee-Man Siu and Chi-Wah Mou 2005) when determining overall satisfaction, whereas the system availability and the fulfillment dimension are not that critical with regard to satisfaction. In line with this reasoning, system availability and fulfillment may instead be related to dissatisfaction when the performance of these is unsatisfactory. 
Obtaining the correct price of the journey was difficult for the majority of the respondents; 57 percent of the respondents did not state a price at all. One explanation for this is that the fare table is zone based. The possibilities of understanding where the zone boundaries are located on the website are limited, so it is not actually possible to determine the price of a journey with any degree of certainty. An explanation for that seven respondents stated the correct price could be that they already knew it.

Although the findings are encouraging and useful, the present study has certain limitations. We selected one public transportation-related information site for our research, which has an effect on the generalizability of our conclusions. The need exists to further examine the perceived service quality and overall satisfaction in the context of more diverse transport information sites. Furthermore, it is necessary in future studies to expand and randomize the sample to fully understand perceived electronic service quality. In future studies, it could also be valuable to add additional questions to capture broader attitudes toward public transport. It is then possible to analyse the impact of satisfaction with public transportation information on the Internet on satisfaction with public transport in general. A more thorough psychometric assessment of the modified scale also needs to be made in future studies.

\section{References}

Aladwani, Adel M., and Prashant C. Palvia. 2002. Developing and validating an instrument for measuring user-perceived web quality. Information and Management 39: 467-476.

Bell, Hudson, and Nelson K. H. Tang. 1998. The effectiveness of commercial internet websites: A user's perspective. Internet Research: Electronic Networking Applications and Policy 8.

Liu, Chang, and Kirk P. Arnett. 2000. Exploring the factors associated with website success in the context of electronic commerce. Information and Management 38: $23-34$.

Mick, David G., and Susan Fournier. 1998. Paradoxes of technology: Consumer cognizance, emotions, and coping strategies. Journal of Consumer Research 25: 123-147. 
Parasuraman, A., Valarie A. Zeithaml, and Arvind Malhotra. 2005. E-S-QUAL a multiple-item scale for assessing electronic service quality. Journal of Service Research 7: 213-233.

Wolfinbarger, Mary, and Mary C. Gilly. 2003. eTailQ: Dimensionalizing, measuring and predicting etail quality. Journal of Retailing 79: 183-198.

Zhang, Ping, and Gisela M. Von Dran. 2001. User expectations and rankings of quality factors in different website domains. International Journal of Electronic Commerce 6: 9-33.

Yang, Z., S. Chai, Z. Zhou, and N. Zhou. 2005. Development and validation of an instrument to measure user perceived service quality of information presenting web portals. Information and Management 42: 575-589.

Yee-Man, Siu Noel, and Jeremy Chi-Wah Mou. 2005. Measuring service quality in Internet banking: The case of Hong Kong. Journal of International Consumer Marketing 17: 99-116.

Yoo, Boonghee, and Naveen Donthu. 2001. Developing a scale to measure the perceived quality of an Internet shopping site (SITEQUAL). Quarterly Journal of Electronic Commerce 2: 31-45.

\section{About the Authors}

LARS ERIKSSON (lars.eriksson@kau.se) is a postgraduate student in psychology at Karlstad University and a researcher at the Service Research Center. His research focus is in the public transport area and includes e-service quality as well as the psychological factors of travel mode choice. He has previously worked in the IT industry for more than 10 years with software development.

Ann-Catrin Norman (ann-catrin@xpress.se), a former student in psychology at Karlstad University, is an investigator/coordinator at the Swedish Social Insurance Agency.

MARGARETA FrIMAN (margareta.friman@kau.se) is an associate professor in psychology and director of the Service and Market Oriented Transport (SAMOT) Research Group at Karlstad University. Her research interests deal with perceived service quality and customer satisfaction in public transport services. 